\title{
The advantages and challenges of neurodiversity employment in organizations
}

\author{
Anna Krzeminska ${ }^{1,2 \star}$, Robert D. Austin ${ }^{3}$, Susanne M. Bruyère ${ }^{4}$ and Darren Hedley ${ }^{5}$ \\ ${ }^{1}$ Department of Management, Macquarie Business School, Sydney, Australia, ${ }^{2}$ Institute for Teaching and Learning \\ Innovation, University of Queensland, Brisbane, Australia, ${ }^{3}$ Ivey Business School, Western University, London, ON, Canada, \\ ${ }^{4}$ Lisa Yang and Hock E. Tan Institute on Employment and Disability, School of Industrial and Labor Relations, Cornell \\ University, Ithaca, US and ${ }^{5}$ LaTrobe University, Melbourne, Australia \\ ${ }^{\star}$ Corresponding author. Email: anna.krzeminska@mq.edu.au
}

The last decade has seen a remarkable opening of new job opportunities for people who are neurodiverse - a subset of the general population that historically has experienced un- and underemployment rates as high as 85-90\% (Roux et al., 2015; Taylor \& Seltzer, 2011). Neurodiversity takes neurological developments traditionally regarded as atypical or even as diagnosable disorders, such as autism or dyslexia, and conceptualizes them as normal human variation (Jaarsma \& Welin, 2012). Proponents of this perspective suggest that many neurodiverse people possess useful talents and are capable of functioning productively in organizations, but are barred from work opportunities because they are, as exemplars of human variation, 'at the edges of the bell curve' (Robison, 2013). The problem, according to this view, is not with neurodiverse people, but with hiring processes that define talent too narrowly, and especially with reliance on job interviews, which are biased against people with atypical manners of interaction. This view accords with early criticisms of employment perspectives viewing diversity as 'the problem' rather than the problem as inappropriate management of diversity (see Härtel \& Fujimoto, 2000). Despite slow uptake of this alternative inclusive view of diversity, its validity is being established with prominent companies, such as SAP, Microsoft, DXC Technology, EY, JP Morgan Chase, and Ford, implementing since 2013 employment initiatives that de-emphasize interviews in favor of new inclusive recruiting approaches that have led to celebrated successes in hiring neurodiverse people. In this special issue, we examine some of the primary benefits that firms have realized as well as the challenges they encountered along the way, underscoring the urgent need for researchers and practitioners alike to identify how employment practices can be transformed to be inclusive for all individuals (cf. Härtel \& Ashkanasy, 2011). In this special issue and our introduction to it, we look at the benefits of these new initiatives to the individual, as well as their societal and potential firm or business benefits.

From the perspective of individuals, work is an integral part of life, providing individuals both economic security and the context in which they can contribute their talents and skills to society and thus anchor themselves in a social role (Saleh \& Bruyere, 2018). Research shows that having a job is an important determinant of self-esteem and provides a critical link between an individual and society (Doyle, Kavanagh, Metcalfe, \& Lavin, 2005). The World Health Organization (WHO) affirms this idea, proclaiming that 'although it is difficult to quantify the impact of work alone on personal identity, self-esteem and social recognition, most mental health professionals agree that the workplace environment can have a significant impact on an individual's mental well-being' (Harnois \& Gabriel, 2000: 5). The WHO recognizes that employment provides time structure, social contact, collective effort and purpose, social identity, and regular activity, which are all essential factors in maintaining a healthy lifestyle. The intangible benefits of increased quality 
of life and personal fulfillment that arise from employment are thus also of considerable consequence (Flower, Hedley, Spoor, \& Dissanayake, 2019; Hedley et al., 2018).

From a societal perspective, obvious tangible benefits are created through the employment and integration of highly talented, but previously excluded parts of the population, creating budgetary improvements by reducing public assistance costs and increasing tax payments each time a previously unemployed person becomes employed (Bruyere \& Barrington, 2012; Hedley, Uljarević, \& Hedley, 2017). Individuals with disabilities make up $15 \%$ of the world's population - that is 1 billion people - and this is likely a significant underestimate (World Bank/World Health Organization, 2011). Notwithstanding being one in five or six globally, people with disabilities are half as likely to be employed as their nondisabled peers. In the United States in 2017, for example, $37 \%$ of working age Americans with disabilities were in the workforce compared to $79 \%$ of people without disabilities. This has remained true despite society and policy makers' efforts to address these issues over the past several decades in protections now afforded increasingly at a national level and international level to address employment discrimination, as well as economic development initiatives designed to address these disparities more systemically in communities (cf. Härtel, Krzeminska, and Carrero, 2019).

Barriers to the employment of people with disabilities parallel those of other minority populations - namely, negative attitudes and stereotypes from supervisors and coworkers, which in turn impact access to work experience and skill development. Adding to the legitimacy of arguments for opening opportunities to people who have been excluded are moral justifications, in terms of fairness, human rights, or imperatives to develop human capabilities (Neesham, Härtel, Coghill, \& Sarros, 2010; Nussbaum, 2011; Mitra, 2006). Advances in civil rights, desegregation, and deinstitutionalization between the 1950s and 1980s in the United States represented a critical time in American policymaking where a significant philosophical shift in addressing societal disparities for people with disabilities was occurring. Disability advocates advanced the theories of normalization, protection and advocacy, independent living, and civil rights and empowerment for people with disabilities. Activists worked to shift policymakers from a viewpoint of persons with disabilities that was based on a medical model of disability and rehabilitation to one based on removal of physical and attitudinal barriers and the provision of functional supports, a move that helped change views of disability as something having as much to do with the environment as the individual (Bruyere \& Barrington, 2012).

Regulatory environments that prohibit discrimination and support vocational training and educational opportunities constitute a critical first step toward addressing these needed philosophical shifts in how people with disabilities are viewed and also ultimately toward their economic independence (Saleh \& Bruyere, 2018). Moral arguments provide an important basis for specific policy objectives, such as the United Nations Convention on the Rights of Persons with Disabilities passed in 2006, which 177 countries have ratified to-date; the United Nation's Sustainable Development Goal 8 ('Promote sustained, inclusive and sustainable economic growth, full and productive employment and decent work for all'); and national legislation, such as the 'Americans with Disabilities Act of 1990' in the United States. An extensive research literature on disability employment is motivated to a substantial degree to advance social good, by providing remedies for situations in which people are perceived by employers not to fit job descriptions because of the so-called 'disabilities' (Bruyère et al., 2016).

For many years, disability issues were more predominantly seen in the literature of clinical and medical fields, as well as disability studies over time. When a focus on employment did begin to emerge, the related research literature on employment for people with disabilities focused heavily on the perspective of people with disabilities and service providers. Reports of studies of attitudes and behavior were primarily published for an audience of service providers and advocates, and much less was being targeted to employers (Karpur, VanLooy, \& Bruyère, 2014). In the past few decades, the issue of disability in the workplace is gaining increasing attention in other disciplinary areas (Colella \& Bruyère, 2011). Employment nondiscrimination legislation, especially 
that necessitating workplace accommodations and adjustments, has broadened the concern over disability and work to other disciplinary fields such as law, sociology, economics, and psychology. Similar legislation in other countries (e.g., England, Australia, Canada) has fueled applied concern and scholarly activity (Colella \& Bruyère, 2011). Related research is only beginning to emerge in work-related psychology and management journals, fueled by the numerous related issues pertaining to the selection, development, and integration of people with disabilities into the workforce that are relevant to the domains of psychology, organizational behavior, human capital development, and effective management (cf. Härtel, Krzeminska, \& Carrero, 2019). Attention to these issues is beginning to incrementally change, and the neurodiversity workplace inclusion initiatives and research described in this special issue are contributing significantly. Employers are looking increasingly to organizational researchers and management scholars for best practices to help them identify how to effectively implement these programs so they can consistently realize the anticipated benefits they are designed to bring about, both for the individual and the organization.

Especially notable in recent discussions of neurodiversity employment is the prevalence of justifications based on arguments about improvements in firm competitiveness (Austin \& Pisano, 2017). Most major companies with established neurodiversity employment programs insist that business justifications are at the heart of their efforts. Claims of business benefit can, of course, be made for disability employment more broadly (and have been; e.g., Kulkarni \& Lengnick-Hall, 2014; Lengnick-Hall, Gaunt, \& Kulkarni, 2008). Many categories of business advantage can arise from employment practices that are fairer, regardless of the basis of past injustices. Not least of these is that many of the people hired despite supposed disabilities perform well in their jobs. Managers also cite public relations and marketing advantages that follow from perceptions that a company is 'doing good' (Pisano \& Austin, 2016a). In addition, companies report seeing, in close proximity to disability employment activities, morale and employee engagement benefits that arise from employees feeling good about working for a company that is 'doing the right thing' (Pisano \& Austin, 2016b).

Other claims of business benefit seem related to the specific character of neurodiverse conditions. For example, the special abilities of people with autism to complete exacting and repetitive tasks, to observe and to recall detail, and to recognize patterns (Austin \& Busquets, 2008; Boucher, 2009) allow them to do valuable work for which others lack patience or similar ability. In some contexts, the ability to focus single-mindedly on a task has been observed to generate substantial productivity benefits (e.g., Austin, 2018). In others, the visceral discomfort some neurodiverse people feel when they encounter disorder or illogic in a business system usefully triggers process improvement efforts (Austin, 2018). SAP managers point to an easing effect on the company's talent scarcity problem in certain key areas (e.g., cybersecurity, business analytics) that overlap appreciably with talents possessed by (some) neurodiverse people; they report also that the talent available from this nontraditional pool has resulted not only in positions filled that otherwise would have gone unfulfilled, but also in access to much higher levels of talent than otherwise would be available (in other words, some neurodiverse employees turn out to be very, very good at their jobs, better than anyone the company thought they would be able to hire; Pisano \& Austin, 2016a). More broadly (and perhaps speculatively), firms with neurodiversity employment programs often claim enhancements in organizational innovation capabilities that are presumed to arise from having employees of different neurological makeup. For example, SAP, in the 2013 press release that announced their program, cited a belief that innovation comes from the edges' (Pisano \& Austin, 2016a). The idea seems to be to harness neurodiversity's potential to create value by generating novel and different outputs, which arise from neuro-atypical individuals' different perspectives, different ways of thinking, and different ways of being. Innovation research provides support for this idea; for example, Jeppesen and Lakhani (2012) who studied people who were successful in solving crowdsourcing challenges found they tended 
to be 'marginal' socially and, with respect to the problem domain, 'in the outer circle' in comparison with others who tried to solve the problem.

Other claimed business benefits are more subtle and intriguing. For example, managers sometimes claim that participating in neurodiversity employment programs 'makes them better managers' (Austin \& Pisano, 2017). The apparent mechanism: managing neurodiverse employees forces managers to shift their thinking toward designing customized working conditions that maximally activate individual talents; and this thinking, if generalized to all employees, results in greater productivity per employee and in aggregate. In a similar vein, the very explicit guidance required to activate the talents of some neurodiverse employees forces companies to communicate more directly and visually, and to codify organizational processes in ways that ultimately benefit all employees, and sometimes facilitates process redesigns (Austin, 2018). The assertion that actions taken to accommodate neurodiverse people often spill over into benefits for all employees is common (Austin \& Pisano, 2017); indeed, one of the papers in this special issue addresses how this happens.

Whether to advance social good or achieve business benefits, some companies have made brisk progress in developing new methods and addressing the challenges that inevitably arise in expanding neurodiversity employment practices. Such activities date back to 2004, when Danish social entrepreneur Thorkil Sonne founded Specialisterne ('The Specialists'), a for-profit consultancy that aimed to tap the special talents of people on the autism spectrum to sell best-in-class services in areas such as software testing and quality control (Austin \& Busquets, 2008). Sonne and his staff developed early versions of hiring and training methods that relied less on interviews and more on exercises that allowed autistic people to demonstrate their talents. These methods were subsequently taken up by pioneering multi-national companies - SAP, Microsoft, and others - and further developed to adapt to their own business needs. Accelerating activity in this nascent area has led to the rapid appearance of new challenges as well as the development of new solutions. While the movement is growing quickly in practice, we lack evidence-based research that scrutinizes the benefits and challenges of integrating neurodiverse talent into organizations.

The purpose of this special issue, then, is to provide a forum for research that could form a scholarly basis for this practice and to encourage further generation and systematization of knowledge on neurodiversity talent management that might find its way into management curricula. Thus, we sought both conceptual and empirical submissions to further inform this newly emerging area of research inquiry. While we remain modest in our expectations of what a single issue can do relative to the volume of work that could be done, and indeed needs to be done in this area, we are nevertheless excited by the bounty our special issue call for papers yielded.

\section{In This Special Issue}

Historically, neurodiversity literature, in any context, has predominately been written from a topdown, medical assistance, or diagnostic view (cf. Härtel, Krzeminska, \& Carrero, 2019). It is rare to come across an account in which neurodiversity employment is viewed through the eyes of autists, who are the founders, and existent leaders, of a respected organization. However, in 'Nothing about us, without us: A case study of a consumer-run organization by and for people on the autism spectrum in the Netherlands,' van den Bosch et al. have provided us with just such an account.

The authors conducted an exploratory study within a consumer-run organization (CRO) known as 'Persons on the Autism Spectrum' in the Netherlands (PAS-Nederland). Over the course of 7 months, semi-structured interviews were conducted with eight autistic staff members to develop a first-hand perspective on autism, self-advocacy, and CROs, as experienced by the autists themselves. After a comprehensive analysis of the data, four themes emerged: 
- Invisibility was defined in both literal and metaphorical forms. Autism is a condition that can display noticeable characteristics, but if the symptoms are comparatively mild, neurological difference may go unnoticed and/or subsequently disregarded. This paper explores the way this kind of invisibility plays out in an organizational setting, the implications for those who experience it and the organization.

- Diversity on the autistic spectrum refers to the vast range of symptomatic manifestations of autism. As one respondent put it: 'If you've met one person with autism, you have met one person.' As it would in any organization, this reality has consequences, which are identified and discussed, in the CRO context.

- Autistic leadership emerged a focal point for a specific reason: contrary to conventional opinion, having autism does not rule out being a leader in the work place. In the case of PAS-Nederland, autistic leaders implemented and managed the organization. This paper examines their experiences in such roles, through their own eyes.

- Collaboration between people with and without autism is a theme based on the search for true equality. It begins with the premise that when making decisions pertaining to neurodivergent employees, sound practice requires inviting a person with autism to the table. This paper suggests how this simple step can make an important difference in organizational efforts by creating opportunities for invaluable feedback that would not otherwise be available.

This article contributes to the literature on neurodiversity employment by providing fresh and important perspectives on how to proceed with future research. As opposed to more conventional research approaches that might, for example, highlight the limitations in executive functioning of autistic employees which interfere with their leadership skills, the conceptual work in this paper proposes more positive framing. As the authors demonstrate, autistic people do possess leadership skills. Better, then, to take an approach that unpacks the work place conditions and/or individual preferences that facilitate autistic leadership, which emphasizes ability rather than disability. Each of the themes that the paper explores similarly suggests alternative frames to move neurodiversity employment research forward in a better way.

Workplace climate for inclusion factors are important for all employees and have been studied extensively as the diversity and inclusion focus for business blossomed over the past two to three decades. It is therefore most appropriate that the next article brings a similar focus to a discussion of what makes a work environment inclusive for neurodiverse individuals, particularly those with autism spectrum disorder. 'Employers' perspectives regarding reasonable accommodations for employees with autism spectrum disorder' by Waisman-Nitzan, Gal, and Schreuer is a qualitative phenomenological study of the results of interviews with 11 employers in Israel, from which insights in three areas emerged: employers' perceptions of employees with ASD, motivation to hire someone with ASD, and accessibility of the work environment in terms of accommodations.

The authors provide an excellent overview of related literature, and shape the contextual framework for their work in the overarching consideration of a 'justice climate' lens of corporate culture, including interpersonal, procedural, and distributive justice. The perceptual focus for employers as derived from interviews revealed two different voices: a productive-organizational voice, emphasizing an examination of the ASD employee's productivity and qualifications for the job (thereby contributing to the profitability of the company); and a social-personal voice, which characterizes the 'profitability' of a neurodiverse hire in terms of increased sensitivity in the surrounding workplace and within the workforce instilled by interpersonal interactions with neurodiverse colleagues. Interestingly, motivations to hire a neurodiverse individual were reported by employers to be a blend of practical and social values; some referenced a requirement to meet a quota, while others cited a moralistic purpose. Every participant remarked on the indirect societal benefit that occurred within their workplace as a result of employing someone with ASD. 
The paper also examines the issue of accessibility within the workplace in two principal areas: the manner in which the job was performed and accommodations made to the surrounding environment. The authors show that proactive preparation of the workplace for the neurodiverse employee and targeted environmental accommodation can positively contribute to successful integration; but they also show that such actions can sometimes, inadvertently, lead to increased stigmatization or even privacy violation in the event of advanced disclosures about a person's neurodiverse condition.

The contributions of this paper extend beyond thematic suggestions of the importance of productivity or spill-over benefits to the cultural work environment. Amid the results of this study is a response from an employer that succinctly captures a central point made by this paper. To paraphrase: all employees have special needs. The idea that making adjustments to the work environment, or to the manner in which the job is done, can maximally activate the possibilities of value creation is not limited to neurodiverse staff members. Working with neurodiverse staff people leads managers to realize that making adjustments to working conditions based on a worker's individuality has its own intrinsic value. Indeed, an avenue for future research would be to quantitatively measure the productivity impact as a result of such adjustments, first to efficaciously showcase an autistic employee's capability, regardless of their disability, but ultimately in terms of aggregate value across all employees.

In 'A Theoretical Framework for Investigating the Context for Creating Employment Success in Information Technology for Individuals with Autism,' Annabi and Locke seek to address current theoretical limitations concerning the neurodiversity and employment literature. They adapt the Organizational Interventions Mitigating Individual Barriers (OIMIB) framework, initially designed to showcase the barriers women face within the IT industry, and apply it to the concept of neurodiversity employment. Within the context of recent hiring drives by multinational IT companies to identify and employ individuals with autism, Annabi and Locke modify the OIMIB framework by synthesizing the literature to identify and define barriers to entering the workforce faced by autistic and other neurodivergent individuals. Without appropriate support or accommodations, employees with autism are forced to rely on coping methods to mitigate barriers - for example, masking symptoms by mimicking the behavior of neurotypical colleagues. Annabi and Locke argue that future research assessing the impacts of inclusive employment needs to be couched within a theoretical framework - their adaptation of OIMIB to the employment of people with autism is an important step toward this goal.

Understanding employment within the context of the neurodiversity movement is relatively new and requires theoretical discourse to guide the empirical investigation. Yet, there is much that can be drawn from existing literature. To this end, Annabi and Locke review and incorporate what is currently known in the autism, diversity and inclusion, and management fields. For example, they provide a thorough review of the barriers to employment faced by employees with autism followed by an analysis of the strengths and benefits they bring to the workplace. This section draws on constructs as broad as corporate responsibility, organizational culture, demand for labor, bias and stereotype, and productivity and innovation.

The application of the OIMIB framework to autism employment programs has clear implications for practice. Employers, while enthusiastic, may not have access to the resources required to facilitate inclusive employment. Furthermore, specific barriers and concerns encountered by those who are neurodivergent may not be as salient to those who are neurotypical. Consequently, despite good intentions, neurodivergent employees may continue to feel pressure to disguise or hide their condition even when the employer actively promotes neurodiversity. Annabi and Locke call for a shift away from restrictive hiring quotas toward the development and implementation of training and education programs for both neurotypical and neurodivergent employees: a move they posit will lead to wide ranging benefits to all stakeholders. They also highlight the need for not overlooking individual differences; a particularly important point given 
the considerable heterogeneity within the autism construct. For practitioners, training serves as an efficacious opportunity to learn about the strengths and weaknesses within the workforce.

In 'Sometimes you just need someone to take a chance on you: An internship programme for autistic graduates at Deutsche Bank,' Remington and Pellicano explore the attitudinal experiences of autistic interns and their hiring managers stemming from a 3-month program at one of the world's largest financial institutions. Using a series of semi-structured interviews, the authors explored the expectations of each participant at the start of the internship. Then, at the conclusion of the program, the interns and managers were re-interviewed about their actual experiences. While a variety of themes were revealed, the format of this study was unexpectedly innovative in the most simplistic way, in that it examined both preconceptions and the attitudinal outcome of a bona-fide work program.

Much of the small volume of research on neurodiverse employment has focused on attitudinal perceptions of organizations towards inclusive hiring; in other words, it has centered on hypothetical scenarios in lieu of actionable experiences. Of the relatively few studies that exist where first-hand experiences are explored, they do not qualitatively include a pre and postemployment assessment to develop a comprehensive view of what kind of attitudinal changes took place. This overt gap within the literature is what Remington and Pellicano have begun to address: moving beyond proverbial preliminary judgments to empirically showcase a before-and-after view from both employer and employee. Additionally, because autistic employment often arises in government-supported contexts, few of which feature large, for-profit multinational companies, scholars have often been restricted in the range of workplaces they have been able to examine. Such studies necessarily raise doubts about the generalizability of their conclusions into for-profit settings. By conducting research within a major financial institution such as Deutsche Bank, these authors obviously get around this limitation.

Prior to the start of the internship program, managers and interns alike were nervous, but in a positive way. They each expressed a desire to create a valuable learning experience. However, they were cognizant in order to do that, a strong support system was needed. There was an awareness among managers that they should not create experiences for neurodiverse interns that contrasted with those of their neurotypical counterparts. Also, each side expressed awareness of opportunities and potential limitations: communication and social challenges were perceived as imminent, but managers appeared ready to adjust for these and to accommodate the interns as necessary.

At the conclusion of the program, the overall view was that the program had been surprisingly successful. Of the eight interns, five had their contracts extended and colleagues expressed beliefs that neurodiversity was a benefit to the company. Managers emphasized ensuring everyone was treated in an unbiased manner and the importance of playing to the strengths of an individual regardless of their neurological makeup. Challenges cited stemmed from environmental factors (e.g., auditory sensitivities) or situational complexities (e.g., social and communication difficulties). Two interns noted needs for increased support. Overall, this article provides valuable insight from first-hand accounts of the experiences of autistic employees and their supervisors in a large, for-profit company, and contributes to our understanding of the advantages and challenges of integrating neurodiverse individuals into organizational contexts.

Finally, 'The DXC Technology Work Experience Program: Disability Inclusive Recruitment and Selection in Action' by Carrero, Krzeminska, and Härtel presents the characteristics of and experiences during a 3-week recruitment and selection process for neurodiverse adults that could demonstrate an aptitude and motivation to perform in IT roles at DXC Technology, one of the largest IT companies in the world and a leader in autism employment. Based on nonparticipatory observation of the program complemented by interviews with key DXC staff, the case study provides a narrative that engages the reader with a set of key questions and challenges DXC was faced with in designing and implementing their work experience programs: How could they design a recruitment and selection strategy for neurodivergent individuals that was equitable, ethical and efficient? In particular, where could they find suitable neurodivergent candidates, what criteria should they 
use to select them and how should they handle unsuccessful candidates to ensure beneficial outcomes for all stakeholders? In addition to providing a useful research case, the article is intended to enable educators/trainers to use the case for learning and development; five discussion questions and proposed answers are provided, which not only ensure effective engagement with the case information, but also with the articles published in this Special Issue as well as the broader literature on autism employment and diversity and inclusion generally. This case study adds to the handful of case studies currently available on the topic, e.g., Wareham and Sonne (2008), Pisano and Austin (2016a, 2016b), and Krzeminska and Hawse (2019).

\section{Broader Theoretical Issues}

We believe that neurodiversity employment programs, while valuable to the world on their own practical terms, also present major opportunities to address theoretical issues within management research. Considered broadly, these programs raise questions about how companies organize for value creation; how they acquire, develop, and harvest employee talent; and whether this is all changing as competitive conditions evolve (e.g., as companies move from efficiency- to innovation-based competition). A statement by Anka Wittenberg, former Chief Diversity and Inclusion Officer for SAP, encapsulates what she believes to be pressing issues:

Our vision is to create an inclusive environment where people can bring their uniqueness to the table. The corporate world has mostly missed out on this. Historically, we've asked people to tailor themselves to fit. But when you do that, people have to leave part of their authentic selves behind, which is too bad because those parts are potentially valuable to us, to SAP. Innovation is most likely to come from those parts of each us that we don't all share. The Autism at Work program is broadly valuable because it has forced us - we have no choice where autism is concerned - to adjust our processes to our colleagues' uniqueness. This teaches us, as managers, something about how we will need to access talent in the future. (quoted in Pisano \& Austin, 2016a).

Embedded within this statement are a number of interesting theoretical propositions, about the way value creation might be changing in response to shifting bases of competition, and about shifts in the tradeoffs between the benefits of employee fit and diversity.

The idea of standardized job roles into which workers should 'fit' is deeply entrenched in management thought, closely tied to foundational notions of industrial revolution value creation and economies of scale. Extension of principles based on the idea of interchangeable components led to ideas of standardized roles and instruction for people, the so-called 'scientific management' (Taylor, 1911). In an efficient mass production system, neither parts nor people could be 'individuals' - they needed to fit, else scale economies would be lost. Managing for standardization had profound downstream effects. Chandler $(1962,1977)$ describes how competition between firms based on scale economies led to the rise of 'managerial capitalism,' notable for its formal definition of job roles embedded in organizational structures. Modern practices in the field of strategic human resource management (see, e.g., Mathis \& Jackson, 2010) follow Chandler's (1962) 'structure follows strategy' principle when they advise deriving organizational structure from strategy, required capabilities from strategic plans, and job descriptions from analysis of these required capabilities. Thus, when modern recruiters seek employees that best fit a checklist for a job that is already defined and assigned a position in an organizational hierarchy - a process that often rules out 'unusual' candidates in a manner analogous to how defective parts are rejected in an industrial system - they act in consistency with a set of management principles with a long, deep history.

Yet, in seeming contrast, we see now an exciting and expanding literature on the benefits of workplace diversity, in gender, ethnicity, migrant status, and disability (e.g., Baldridge \& 
Kulkarni, 2017; Fujimoto, Rentschler, Le, Edwards, \& Härtel, 2014; Fujimoto \& Härtel, 2017; Härtel, Härtel, \& Trumble, 2013; Lu, Samaratunge, \& Härtel, 2015) and now in neurological makeup (e.g., this special issue; Härtel, Krzeminska, \& Carrero, 2019). Wittenberg's statement clearly embraces the hypothesis that diverse teams or organizations might perform better than more homogeneous ones, but this depends on effective inclusive management practices (Härtel, 2004; Härtel \& Fujimoto, 2000). In an organization the size of SAP, her conviction seems in conflict with the traditional industrial idea that realizing and maintaining economies of scale requires protecting efficiency from perils of individuality. Whereas managerial capitalism called for managing roles, not people, the benefits from neurodiversity programs seem to suggest that managing people as individuals might sometimes be the better path. But when and where? In what conditions? What has changed, or is changing?

These are big questions, of great theoretical importance to organizational research, and they underscore the need to put as much emphasis on studying the context of a business phenomenon as the phenomenon itself (see Härtel \& O'Connor, 2014 for an in-depth discussion of the importance of context in organizational research). We submit that neurodiversity employment programs provide a natural place to study such questions. As Wittenberg states, managers of neurodiverse employees have no choice but to manage these employees as individuals. Managing in this way frequently causes managers to adopt a philosophy of managing all their employees as individuals, based on the belief that such a philosophy is beneficial in business terms. What should we conclude from this? Taken far enough, such ideas undermine many of the presumptions that underlie even the terms in which we discuss issues of managing people and talent. The idea that people are 'human resources' presumes a fungibility of the stuff of humanity, and an interchangeability of individual people, that Wittenberg and others seem to increasingly think it is unprofitable to believe in. Management research clearly needs to follow this thread, to see where it leads.

Acknowledgements. The Editorial team would like to thank Prof. Charmine E. J. Härtel for commissioning this Special Issue, providing a platform to bring global attention to this important topic. We would further like to thank all reviewers who kindly gave their time and expertise in supporting us to select and develop the manuscripts in this issue.

\section{References}

Annabi, H., \& Locke, J. (2019). A theoretical framework for investigating the context for creating employment success in information technology for individuals with autism. Journal of Management \& Organization 25(4), 499-515, doi: 10.1017/jmo.2018.79

Austin, R. D. (2018). Hart Schaffner Marx: Neurodiversity employment at a classic American suit maker, Ivey Business School case 9B14C048.

Austin, R. D., \& Busquets, J. (2008). Managing Differences. MIT Innovations, 3(1), 28-35.

Austin, R. D., \& Pisano, G. P. (2017). Neurodiversity as a competitive advantage. Harvard Business Review, 95, 96-103.

Baldridge, D. C., \& Kulkarni, M. (2017). The shaping of sustainable careers post hearing loss: Toward greater understanding of adult onset disability, disability identity, and career transitions. Human Relations, 70(10), 1217-1236. https://doi.org/10. $1177 / 0018726716687388$

Boucher, J. (2009). The autistic spectrum. Characteristics, causes, and practical issues. Los Angeles: Sage Publications.

Bruyere, S., \& Barrington, L. (2012). Employment and work. Los Angeles, CA: Sage Reference.

Bruyère, S. M., VanLooy, S., von Schrader, S., \& Barrington, L. (2016). Disability and employment: Framing the problem and our transdisciplinary approach. Disability and employer practices: Research across the disciplines, 1-26.

Carrero, J., Krzeminska, A., \& Härtel, C. E. J. (2019). The DXC technology work experience program: disability-inclusive recruitment and selection in action. Journal of Management \& Organization 25(4), 535-542. https://doi.org/10.1017/ jmo.2019.23

Colella, A., \& Bruyère, S. (2011). Disability and employment: New directions for industrial/organizational psychology. In American psychological association handbook on industrial organizational psychology (Vol. 1. pp. 473-503). Washington, DC: American Psychological Association.

Chandler, A. D. (1962). Strategy and structure: Chapters in the history of the American enterprise. Massachusetts Institute of Technology Cambridge, 4(2), 125-137.

Chandler, A. D. (1977). The visible hand. Cambridge, MA: Harvard University Press. 
Doyle, C., Kavanagh, P., Metcalfe, O., \& Lavin, T. (2005). Health impacts of employment: A review. Dublin, Ireland: The Institute of Public Health in Ireland. Retrieved from https://www.publichealth.ie/publications/healthimpactsofemployment areview.

Flower, R. L., Hedley, D., Spoor, J. R., \& Dissanayake, C. (2019). An alternative pathway to employment for autistic jobseekers: A case study. Journal of Vocational Education \& Training, Special Issue: Vocational Education and Workers with Disability, 71, 407-428. http://dx.doi.org/10.1080/13636820.2019.1636846.

Fujimoto, Y., \& Härtel, C. E. J. (2017). Organizational diversity learning framework: Going beyond diversity training programs. Personnel Review, 46(6), 1120-1141. http://dx.doi.org/10.1108/PR-09-2015-0254.

Fujimoto, Y., Rentschler, R., Le, H., Edwards, D., \& Härtel, C. E. (2014). Lessons learned from community organizations: Inclusion of people with disabilities and others. British Journal of Management, 25(3), 518-537.

Harnois, G., \& Gabriel, P. (2000). Mental health and work: Impact, issues and good practices. (Nations for Mental Health publication). Geneva, Switzerland: World Health Organization. Retrieved from GLADNET Collection at https://digitalcommons.ilr.cornell.edu/gladnetcollect/222/.

Härtel, C. E. J. (2004). Towards a multicultural world: Identifying work systems, practices and employee attitudes that embrace diversity. The Australian Journal of Management, 29(2), 189-200.

Härtel, C. E. J., \& Ashkanasy, N. M. (2011). Healthy human cultures as positive work environments. In N. M. Ashkanasy, C. P. M. Wilderom \& M. F. Peterson (Eds.), The handbook of organizational culture and climate (2nd ed., pp. 85-100). Thousand Oaks, CA: Sage Publications, Inc. ISBN: 9781412974820.

Härtel, C. E. J., \& Fujimoto, Y. (2000). Diversity is not the problem - openness to perceived dissimilarity is. Journal of Management and \& Organization, 6(1), 14-27. https://doi.org/10.1017/S1833367200005484. Published online: 01 September 2015, pp. 14-27.

Härtel, C. E. J., Härtel, G. F., \& Trumble, R. B. (2013). IDADA: The individual difference approach to assessing and developing diversity awareness. Journal of Management and Organization, 19(1), 60-74.

Härtel, C. E. J., Krzeminska, A., \& Carrero, J. (2019). Disabled persons in the workplace. In J. Syed \& M. Ozbilgin (Eds.), Managing diversity and inclusion: An international perspective (2nd ed.). Los Angeles, CA, USA: Sage.

Härtel, C. E. J., \& O'Connor, J. M. (2014). Contextualizing research: Putting context back into organizational behavior research. Journal of Management \& Organization, 20(4), 417-422. doi: 10.1017/jmo.2014.61.

Hedley, D., Cai, R., Uljarević, M., Wilmot, M., Spoor, J., Richdale, A., \& Dissanayake, C. (2018). Transition to work: Perspectives from the autism spectrum. Autism, 22, 528-541.

Hedley, D., Uljarević, M., \& Hedley, D. F. E. (2017). Employment and living with autism: Personal, social and economic impact. In S. Halder \& L. C. Assaf (Eds.), Inclusion, disability and culture: An ethnographic perspective traversing abilities and challenges. New York: Springer, 295-311.

Jaarsma, P., \& Welin, S. (2012). Autism as a natural human variation: Reflections on the claims of the neurodiversity movement. Health Care Analysis, 20(1), 20-30.

Jeppesen, L. B., \& Lakhani, K. (2012). Marginality and Problem-Solving Effectiveness in Broadcast Search. Organization Science 21(5), 1016-1033.

Karpur, A., VanLooy, S., \& Bruyère, S. (2014). Employer practices for employment of people with disabilities: A literature scoping review. Journal of Rehabilitation Research, Policy and Education, 28(4), 225-241. Retrieved from http://www.ingentaconnect.com/content/springer/rrpe/2014/00000028/00000004/art00003.

Kulkarni, M., \& Lengnick-Hall, M. (2014). Obstacles to success in the workplace for people with disabilities: A review and research agenda. Human Resource Development Review, (June), 13(2), 158-180.

Krzeminska, A., \& Hawse, S. (in press). Autism spectrum employees: Mainstreaming neurodiversity for an inclusive and sustainable future workforce. In Y. Breyer, L. P. Tan, \& L. Wood (Eds.), Industry and higher education: Case studies for a sustainable future. Singapore: Springer.

Lengnick-Hall, M., Gaunt, P., \& Kulkarni, M. (2008). Overlooked and underutilized: People with disabilities are an untapped human resource. Human Resource Management, 47(2), 255-273.

Lu, Y., Samaratunge, R., \& Härtel, C. E. J. (2015). Predictors of acculturation attitudes among professional Chinese immigrants in the Australian workplace. Journal of Management \& Organization, 22(1), 49-67. doi: 10.1017

Mitra, S. (2006). The Capability Approach and Disability. Journal of Disability Policy Studies 16(4), $236-247$.

Mathis, R., \& Jackson, J. (2010). Human Resource Management. Cengage Learning.

Neesham, C., Härtel, C. E. J., Coghill, K., \& Sarros, J. C. (2010). Profit-making vs human value: Philosophy's contribution. Equality, Diversity and Inclusion: An International Journal, 29(6), 593-608. doi: 10.1108/02610151011067522.

Nussbaum, M. (2011). Creating Capabilities: The Human Development Approach. Cambridge, MA: The Belknap Press of Harvard University Press.

Pisano, G. P., \& Austin, R. D. (2016a). SAP SE: autism at work. Harvard Business School Case Study 9-616-042, January 19, 2016.

Pisano, G. P., \& Austin, R. D. (2016b). Hewlett Packard Enterprise: The Dandelion Program. Harvard Business School Case Study 9-617-016, September 8, 2016. 
Remington, A. \& Pellicano, E. (2018). 'Sometimes you just need someone to take a chance on you': An internship programme for autistic graduates at Deutsche Bank, UK. Journal of Management \& Organization 25(4), 516-534, doi:10.1017/ jmo. 2018.66

Robison, J. E. (2013). What is neurodiversity? Psychology Today, 2013. Retrieved from https://www.psychologytoday.com/us/ blog/my-life-aspergers/201310/what-is-neurodiversity

Roux, A. M., Shattuck, P. T., Rast, J. E., Rava, J. A., \& Anderson, K. A. (2015). National autism indicators report: Transition into young adulthood. Life Course Outcomes Research Program', AJ Drexel Autism Institute, Drexel University, Philadelphia, PA.

Saleh, M., \& Bruyere, S. (2018). Leveraging employer practices in global regulatory frameworks to improve employment outcomes for people with disabilities. Social Inclusion, 6(1), 18-28. doi: 10.17645/si.v6i1.1201. Retrieved from https://www. cogitatiopress.com/socialinclusion/article/view/1201

Taylor, F. W. (1911). The Principles of Scientific Management. NY: Harper \& Brothers.

Taylor, J. L., \& Seltzer, M. M. (2011). Employment and post-secondary educational activities for young adults with autism spectrum disorders during the transition to adulthood. Journal of autism and developmental disorders, 41(5), 566-574.

van den Bosch, K. E., Krzeminska, A., Song, E. Y., van Hal, L. B. E., Waltz, M. M., Ebben, H., \& Schippers, A. P. (2018). Nothing about us, without us: A case study of a consumer-run organization by and for people on the autism spectrum in the Netherlands. Journal of Management \& Organization 25(4): 464-480. doi:10.1017/jmo.2018.54

Wareham, J., \& Sonne, T. (2008). Harnessing the power of autism spectrum disorder (Innovations Case Narrative: Specialisterne). Innovations: Technology, Governance, Globalization, 3(1), Winter 2008, 11-27. https://doi.org/10.1162/itgg.2008.3.1.11

Waisman-Nitzan, M., Gal, E., \& Schreuer, N. (2018). Employers' perspectives regarding reasonable accommodations for employees with autism spectrum disorder. Journal of Management \& Organization 25(4), 481-498, doi: 10.1017/ jmo.2018.59

World Bank/World Health Organization (2011). World report on disability. Geneva, Switzerland: Authors. Retrieved from https://www.who.int/disabilities/world_report/2011/report.pdf.

Cite this article: Krzeminska A, Austin RD, Bruyère SM, Hedley D (2019). The advantages and challenges of neurodiversity employment in organizations. Journal of Management \& Organization 25, 453-463. https://doi.org/10.1017/jmo.2019.58 